\title{
Co-living spaces - The new paradigm shift in the Indian Real Estate Market
}

\author{
Dr. J. Joshua Selvakumar ${ }^{1}$, Arthi T $S^{2}$, Suganya $G^{3}$ \\ \{jjs.mba@psgtech.ac.in ${ }^{1}$, arthichic@gmail.com ${ }^{2}$, suganya@psgim.ac.in ${ }^{3}$ \} \\ Associate professor, PSG Institute of management, Coimbatore, Tamil Nadu, India ${ }^{1,3}$, Research Scholar, \\ Anna University, Chennai, Tamil Nadu, India ${ }^{2}$
}

\begin{abstract}
The study examines the consumer perception towards the concept of Co-living spaces in Coimbatore region of Southern India, and probe objectively the factors that help or obstruct in preference towards Co-living spaces over conventional residence. The exorbitant costs of land and an undeniably lone way of life have lead individuals to look for better approaches for living. Co-living is an advanced type of lodging where occupants share living space and a lot of interests, values, and also objectives. The major focus of the study is the find the awareness and preference of consumers towards the concept of Co-Living and identify the factors that influence a person for residing in a coliving setup.
\end{abstract}

Keywords: Co-living housing, Real estate, Shared living, Lifestyle, Behavioral shift.

\section{Introduction}

Co-living aims interpretation of an old thought, envisioned by a millennial age that qualities things like transparency and joint effort, interpersonal interaction, and the sharing economy.

These days, youthful alumni - for whom the allure is frequently monetary - track down an extraordinary specialty in the co-living business sector. Unfit to bear the cost of the exorbitant rents in huge urban areas, they discover the arrangement in sharing. Notwithstanding, these individuals are looking for places that are better-kept up with, better-organized and all the more strategically placed. Co-living spaces - planned and oversaw by organizations spent significant time in house-sharing - are an undeniably famous choice in this specialty. Rather than searching for level mates, and managing shared agreements and bills, one can essentially lease a dorm in one of these turns of events. The vast majority of them offer pre-outfitted and embellished rooms, public conveniences - including kitchens, social regions, and collaborating spaces - just as expert cleaning administrations and surprisingly friendly laborers accessible to assist the occupants with adjusting their new areas.

Generally, co-living is a social qualification, as it can incorporate numerous primary structures, including rental and possession, metropolitan and provincial. All things considered, in its present encapsulation, co-living will in general be metropolitan and incorporated into a solitary structure, house or loft. This idea arose in Denmark during the 1970s - initially under the name of cohousing. The Sættedammen drive, for instance, comprised of 35 families living 
in private homes while sharing common spaces for mingling and exercises, like feasting, housekeeping, bunch social affairs, celebrations, and different occasions.

All the more as of late, the terms deliberate local area and eco-town have become well known. Both will in general be country and land-based models of local area living, with a solid spotlight on maintainable living. Confusingly, deliberate local area has become famous as an overall term for mutual living also.

Then, at that point, there's cohousing. Cohousing is a particular sort of deliberate local area brought over from Denmark in the last part of the '60s. It will in general be rural or provincial, comprising of little private homes that share a typical building(s), regularly with a kitchen, lounge area, and visitor rooms. The people group is arranged, claimed and overseen by the inhabitants, and dynamic is agreement based.

To wrap things up, there is the center house. "Centers" are an outgrowth of the understudy agreeable development, and are regularly found at or encompassing significant schools and colleges. Socially, they will in general be based on communist standards and political activism. At times, they are likewise agreeably possessed, however this isn't a necessity. Communities as a rule could be viewed as co-living, however they may not self-relate to the term. India is a socially assorted country with individuals from various convictions, religion, political belief systems, dialects, race, standing and ideology. There exists an inquiry whether the idea of co living dominates in a nation like India where the Indian populace are high list.

\section{Literature Review}

The markets for residential houses is rapidly changing according to Maalsen who is the pioneer in the concept of co-living. people today in India a welcoming the concept of smart housing. The smart housing concept comprises of the following dimensions; strategy and lodging hacks, savvy economies driving brilliant lodging needs, lodging on request and new sharing economies Maalsen (2019). This shift in the Indian housing sector is due to fact that the cities are getting more smarter and greater investments by the government to create more technologically advanced cities (Tomal, M. 2020).

Though the primary reason in co-living is to share a living space, it likewise targets building connections between occupants (Shafique, 2018). The co-living energizes the inclusion of occupants and components broad shared office (Green and McCarthy 2015) ). Also the design style of co-living structures support community engagement (Ataman \& Dino, 2019 ) and they are often managed and operated by external entities who supervise the property (Fix \& Lesniak, 2017). These co-living facilities are located both in rural and urban areas and support residents with common work places (Bouncken, Clauss \& Reuschl, 2016).

In the Indian context this concept has been triggered by large-scale immigration from the rural areas to the cities, placing pressure on the limited housing facilities available and the rising cost of real estate property. The rising millennial demographics and the ever growing millennial population in India which are the biggest share of the global workforce has caused rental rates to shoot up and has brought about acute shortage scarcity of micro units in desired places (Nandan, Rathi, Grover, \& Lalchandani, 2019). 
The most recent couple of years have seen an enormous expansion on the lookout for coliving industry both in India and in countries of Western Europe, United states and in Asia (Cushman and Wakefield 2019). Builders and Real estate engineers have reacted to the interest for an elective lodging models with shared offices and normal spaces (Tummers 2017). Real estate developers and investors value financial returns as the most important consideration for assessing investment options followed by projects and products that offer high returns with limited risk. This is precisely the reason for co-living spaces to gain importance over the last few years. In recent times the multifamily developers have started to reduce unit measures and need to construct studio or one room units to amplify their lease per square foot (Molla 2019; Mejia 2015). Also in recent years the availability of capital has increased resulting in the increase in the supply side of co-living spaces. Countries like the United States and India have experiences a surge in the real estate market and also appreciation in the value of the properties. This has led to the investors to focus their funds to new and upcoming business models in the real estate space (Deloitte, 2018).

The main reason for the preference of co-living practices in European countries is to discover better approaches for living that can satisfy the necessities of the socio-segment advancements like ageing population, gender roles, sustainability agenda, emerging lifestyle, ethnic diversity (Carriou C, Czischke D and Lang R, 2015)

\subsection{Hypotheses}

H1: There exists a relationship between an individual's demographic characteristics and awareness for Co-Living spaces

H2: There is a strong preference for co-living spaces among the Indian population.

H3: Co-Living spaces are feasible investment options in the long term

\subsection{Objectives}

- To evaluate whether co living spaces would be acceptable in Indian cultural scenario.

- To measure the awareness level of people towards co-living spaces

- To understand the factors influencing people in preferring co living spaces

- To find out the feasibility of co-living spaces in short term and long term.

\section{Methodology}

The research is descriptive in nature and attempts to determine the perception of people towards co-living spaces. The type of research is descriptive as it principally centers around depicting the idea of the segment fragment, in the sense it generally portrays the subject of the exploration instead of covering 'why' it occurs. This examination characterizes the attributes of the respondents and validate the existing conditions. The population consists of people who are looking forward for a new place of dwelling in the near future. Non-probability convenient sampling is chosen. The reason behind this is that the study can have flexibility and freedom in selecting sampling as per convenience. Power analysis was used to determine the size of the sample.

$\chi^{2}$ tests - Goodness-of-fit tests: Contingency tables

Analysis: A priori: Compute required sample size 
Input: Effect size $w=0.4$

$\alpha$ err prob $=0.05$

Power $(1-\beta$ err prob $)=0.85$

$\mathrm{Df}=5$

Output: Non-centrality parameter $\lambda=14.4000000$

Critical $\chi^{2}=11.0704977$

Total sample size $=90$

Actual power $=0.8502673$

Survey method had been incorporated for primary data collection. A structured questionnaire was used for collecting the responses.

\section{Results and Discussion}

H1: There exists a relationship between an individual's demographic characteristics and awareness for Co-Living spaces

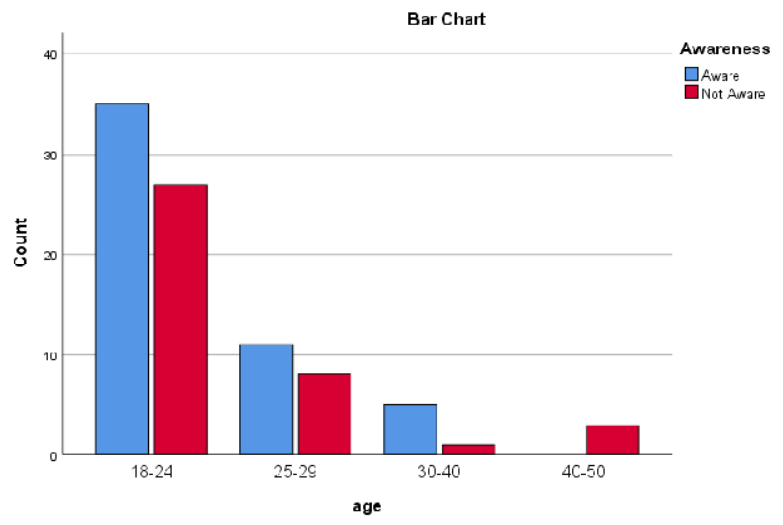

Fig 1: Awareness level of co-living spaces among the various age groups

Here the $\mathrm{P}$ value is 0.049 which is less than 0.05 , hence there is relationship between age and awareness of co-living spaces. The millennial generation are more aware of the concept than older people. 


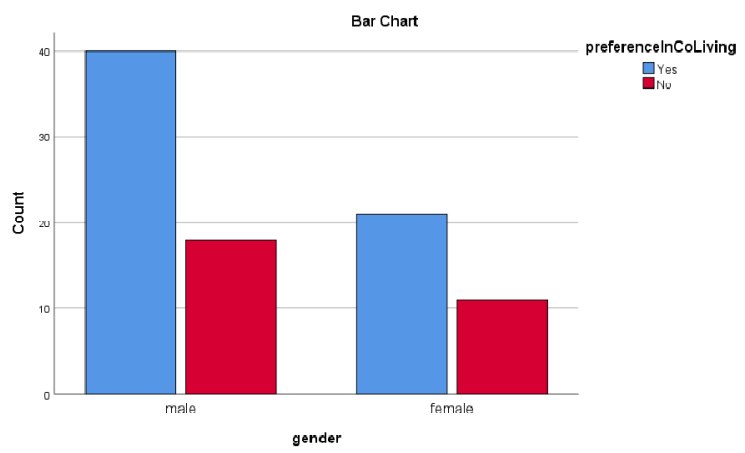

Fig 2: Gender preference for co-living spaces

$\mathrm{P}$ value is 0.079 . Gender does not influence in preference towards Co-Living spaces.

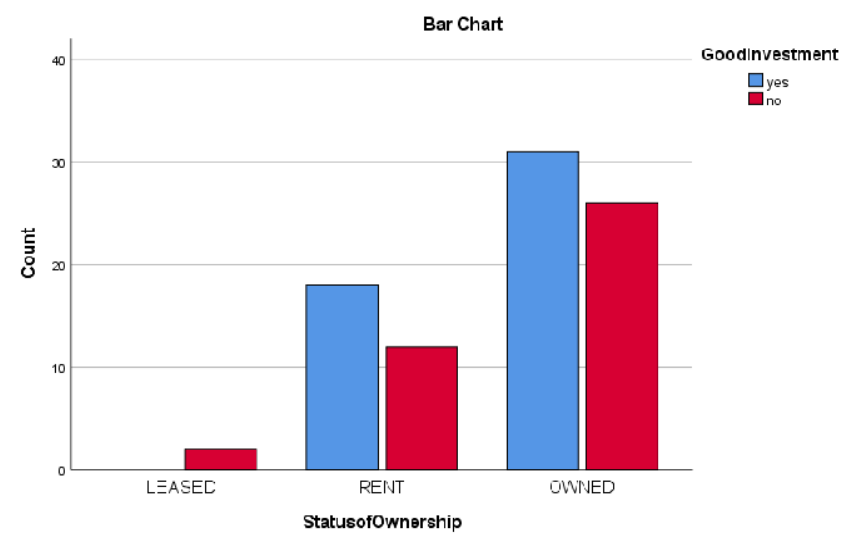

Fig 3: Relationship between ownership and investment

Here the $\mathrm{P}$ value is 0.065 . It can be understood that status of ownership does not influence the investment preference towards Co-Living spaces.

H2: There is a strong preference for co-living spaces among the Indian population. 

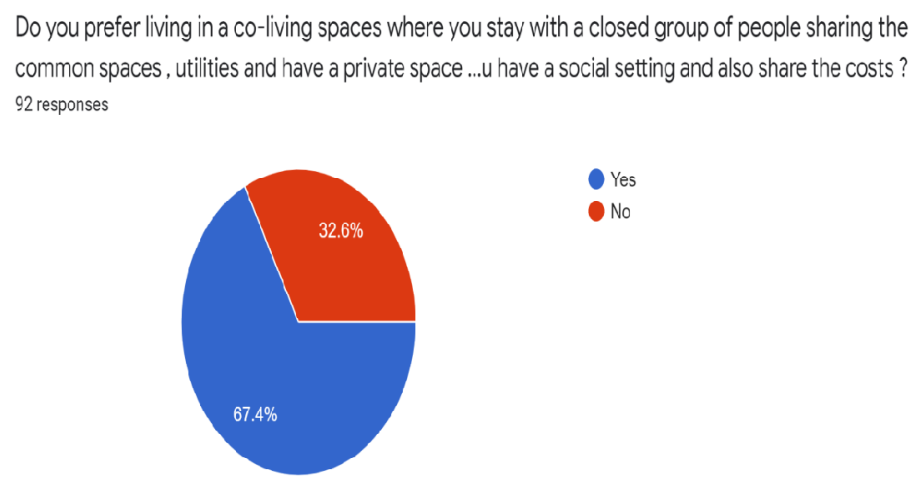

Fig 4: Preference for Co-living sp

aces

Nearly $67 \%$ of the response group preferred the concept of Co-Living spaces.

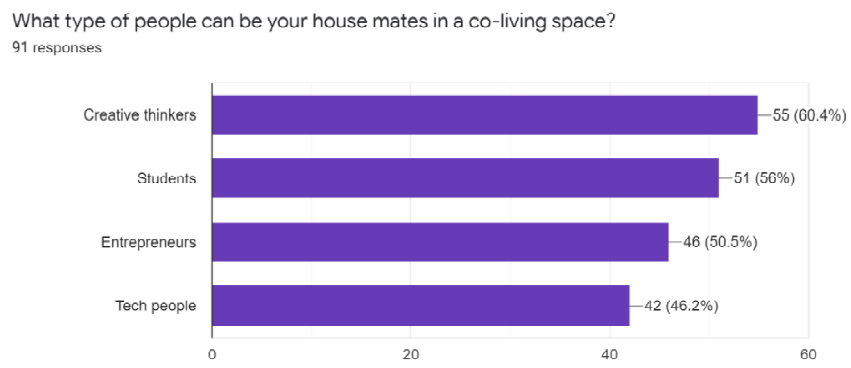

Fig 5: Preference for house mates in co-living spaces

From the responses, we can conclude than Creative people are the most preferred housemate in a Co-Living space.

H3: Co-Living spaces are feasible over the long term

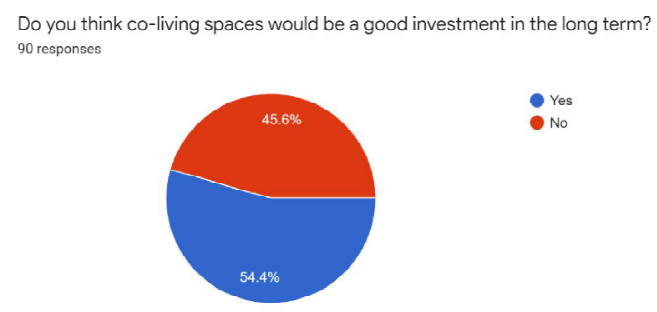

Fig 6: Preference for Co-living spaces as an investment option in the long run 
Nearly $54.4 \%$ of the respondents feel that it is a good investment option in the long run.

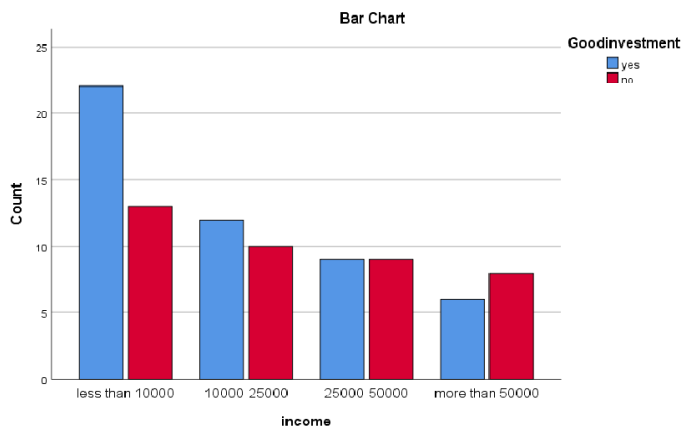

Fig 7: Relationship between income and preference for co-living spaces

The $\mathrm{P}$ value is 0.495 . As the income increases, there is less chance that a person would adapt to live in a Co-Living setup.

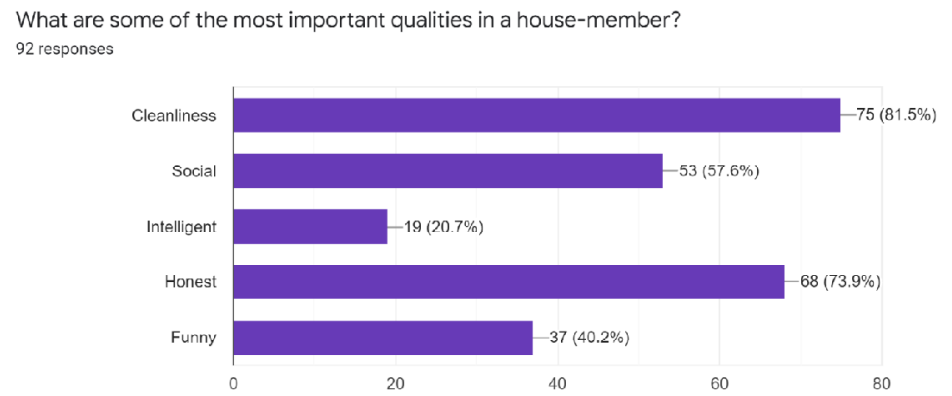

Fig 8: Preference regarding a house member in a co-living space

It can be observed from the survey that over $81.5 \%$ of the respondents had preferred Cleanliness as the most important quality of a house-member in a Co-living space. 


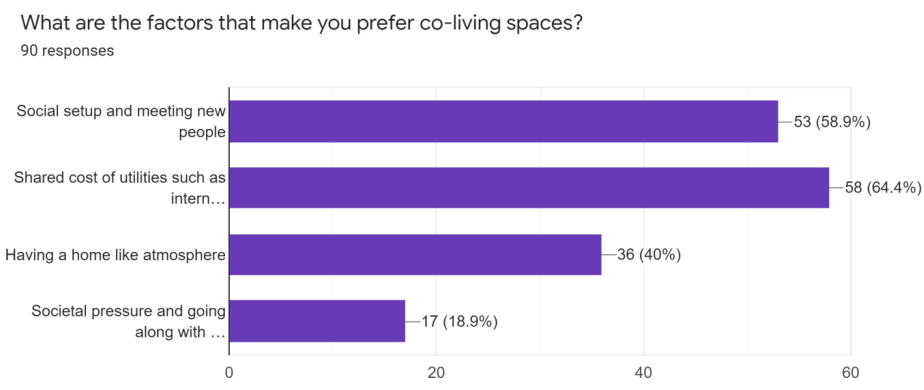

Fig .9 Reasons for the preference of co-living space

A greater part of individuals have liked to decide on a Co-living space due to the advantage of Shared expense of Utilities, for example, web and lower cost and not for the social arrangement and meeting new individuals.

\subsection{Implications of the Research}

Co-living spaces, as a novel concept in India will be a success as over $60 \%$ of the population work at places away from their hometown. They would prefer Co-living space as a short-term home where they would stay for rent. Indians do not prefer Co-living as their primary home as they have a restriction to their personal privacy.

This data is beneficial for real estate developers, investors, government housing board and other government organizations to provide a much needed boost to the slump the real estate industry is facing. Co-living spaces would be a good investment especially in tier 1 and tier 2 cities where people migrate for work opportunities. A low cost co-living setup will also help to provide housing for the backward classes of people who could not afford proper homes. A co-living space is cheaper to afford than conventional housing and also all the work and maintenance costs are also shared among the residents of the co-living setup.

\section{Conclusion}

The study on consumer behavior towards the concept of Co-Living housing gives greater opportunities to learn about the customer's preferences and perception towards community living. Since India is a Real Estate crisis at this point of time with over 2 million unsold housing units. This concept of Co-living aims to bridge the gap of affordable housing to the Indian masses. There is an enormous opportunity for this concept to kick off in a large scale in a densely populated country like India. This growth is directly proportional to the urbanization. The recommendation from this study will be useful for investors, real estate developers and construction companies. All attributes related to the concept were clearly brought into the picture with relevant statistics. Customer's perception and expectation varies over a period of time and this study should be continuous over different period of time to unleash the gap in understanding to consumer perception towards Co-Living spaces.

\section{References}


[1] Ataman, C., \& Dino, I. G. (2019, July). Collective Residential Spaces in Sustainability Development: Turkish Housing Units within Co-Living Understanding. In IOP Conference Series: Earth and Environmental Science (Vol. 296, No. 1, p. 012049). IOP Publishing.

[2] Brown, M. G., \& Roulac, S. E. (2004). Why Can't a Building Be More Like a Machine? Real Estate Issues, 29(1)

[3] Bouncken, R. B., Clauss, T., \& Reuschl, A. J. (2016). Coworking-spaces in Asia: A business model design perspective. SMS. Hong Kong.

[4] Businessline, B. D., \& Jan, C. C. (2018). In co-living space , millennials find a home, 20182019.

[5] Carriou C, Czischke D and Lang R 2015 Collaborative Housing European Network for Housing Research

[6] Drobnis, D. S. (2018). Implementing innovation in real estate development: co-living as an innovative product (Doctoral dissertation, Massachusetts Institute of Technology).

[7] Fix, R., \& Lesniak, M. (2017). The present and future of co-living typologies and business models.

[8] Fowler, A. R., \& Lipscomb, C. A. (2010). Building a sense of home in rented spaces. International Journal of Housing Markets and Analysis, 3(2), 100-118. https://doi.org/10.1108/17538271011049722

[9] Global, N., Blogs, B., \& Dec, C. N. (2018). The Hindu Business Line : Millennials prefer coliving spaces : Survey, 2-3.

[10] Green, S., \& McCarthy, L. (2015). Is sharing the solution?: exploring the opportunities and challenges of privately rented shared accommodation for single people in housing need. People, place and policy, 9(3), 159-178.

[11] Hafström, U. (2021). Coliving in the Sustainable City-A study of coliving as a sustainable urban housing strategy in Stockholm.

[12] Jones, D., News, I., York, N., \& York, N. (2019). Co-Living Spaces Get a Family Focus -WSJ, $1-3$.

[13] Klein, D. (2020). Co-Living Assessed in a Time of COVID-19: Critical Intervention or Millennial Fad?. U. St. Thomas JL \& Pub. Pol'y, 14, 158.

[14] Maalsen, S. (2019). Smart housing: The political and market responses of the intersections between housing, new sharing economies and smart cities. Cities, 84, 1-7.

[15] Monitor, A. N. (2016). United States : In New York, Co-Living Spaces Create Options for Singles, New Arrivals, 1-3.

[16] Molla, R. (2019). Co-living" is the new "having roommates"-with an app. Vox. May, 29, 2019.

[17] Mcgriff, D., Schools, N., \& Fund, V. (2011). Are We Ready for, (1990), 2-4. Retrieved from http://files.eric.ed.gov/fulltext/ED540357.pdf

[18] Sardinha, B., \& Carvalho, L. (2007). Housing cooperatives in Portugal - The end of social purposes. REVESCO: Revista de Estudios Cooperativos, (91), 34-59. https://doi.org/10.5209/REVE.19907

[19] Shafique, A. Co-Living and the Common Good; RSA: London, UK, 2018

[20] Sanghani, R. H. (2020). CO-LIVING SPACES IN INDIA. International Journal of Management, 11(10).

[21] Svistovski, F. (2019). Burning Down the Housing Market: Communal Living in New York. Fordham Urb. LJ, 47, 463.

[22] Theriault, L. (2010). "Not Just an Apartment Building": Residents' Quality of Life in a Social Housing Co-operative. Canadian Journal of Nonprofit and Social Economy Research, 1(1), 82-101. https://doi.org/10.22230/cjnser.2010v1n1a37

[23] Tantia, S., \& Arya, P. (2020). Till Distance Keeps Us Apart-Does The Future Of Co-Living Look Bright After The Pandemic?. Psychology and Education Journal, 57(9), 4370-4380.

[24] Tomal, M. (2020). Moving towards a smarter housing market: The example of poland. Sustainability, 12(2), 683. doi:http://dx.doi.org/10.3390/su12020683 
[25] Tummers, L. (2015). Understanding co-housing from a planning perspective: why and how? Urban Research \& Practice, 8:1, 64-78

[26] Wuidart, L. (1997). Living in HARMONY. New Electronics, 30(1), 44-45. https://doi.org/10.3167/jemms.2014.060204

[27] Wall, R., Journal, S., York, N., York, N. Y. N., \& Nov, N. Y. (2016). London' s' Generation Rent 'Tries Co-Living ; Young professionals are opting for " co-living " -- renting a bedroom in a building with communal spaces. In London, co-living developments are getting bigger and pricier ., 2-5. 